\title{
Fracture Energy of Foamed Concrete: Numerical Modelling Using the Combined Finite-Discrete Element Method
}

\author{
Z. M. Jaini ${ }^{1,}{ }^{*}, N$. Abd Rahman ${ }^{1}$, R. H. M. Rum ${ }^{2}$, and M. M. Haurula ${ }^{2}$ \\ ${ }^{1}$ Jamilus Research Center, Universiti Tun Hussein Onn Malaysia, 86400 Parit Raja, Johor, Malaysia \\ ${ }^{2}$ Faculty of Civil and Environmental Engineering, Universiti Tun Hussein Onn Malaysia, 86400 Parit \\ Raja, Johor, Malaysia
}

\begin{abstract}
Foamed concrete is known as lightweight concrete that proven in the low range of densities with good strength. Numerous studies were conducted to investigate its performance in term of mechanical properties. However, these investigations are still not adequate in the requirement of failure and damage mechanisms. This is due to the lack of knowledge on fracture energy that governs the crack resistance of foamed concrete. Therefore, this paper presents the numerical prediction of fracture energy of foamed concrete using the combined finite-discrete element method. The notched beam was modelled in the two-dimensional with unstructured mesh elements and a simple material model of Rotating Crack. The results of numerical prediction signify that various notch depths have an apparent impact toward fracture energy of foamed concrete.
\end{abstract}

\section{Introduction}

Fracture energy refers to the most important material property that governs the cracking and failure behaviour, especially for brittle materials. In general, the initiation, growth and propagation of crack are highly associated with fracture energy. Therefore, fracture energy reflects the toughness and crack resistance of material to sustain particular actions. Fracture energy is highly influenced by size effects, mostly dependent on the dimension, geometry and shape of structure, loading condition as well as the present of reinforcements. However, other factors such as strength, particle distribution and mix proportion of materials have also play a major role.

Normal concrete has fracture energy of approximately $75 \mathrm{~N} / \mathrm{m}$ to $100 \mathrm{~N} / \mathrm{m}$ and increases as high as $200 \mathrm{~N} / \mathrm{m}$ for high-performance concrete. Meanwhile, the fracture energy of foamed concrete, including cellular concrete and aerated concrete, was found to be $30 \%$ to $50 \%$ lower than normal concrete [1]. Void and non-presence of coarse aggregate typically affected the strength and consequently reduced the fracture energy of foamed concrete. However, the strength of foamed concrete also highly depends on its density, which varies from $400 \mathrm{~kg} / \mathrm{m}^{3}$ to $1800 \mathrm{~kg} / \mathrm{m}^{3}$. Abd Rahman et al. [2], Kozlowski et al. [3] and Jaini et al. [4] suggested that the fracture energy of foamed concrete is within $1.5 \mathrm{~N} / \mathrm{m}$ to $35 \mathrm{~N} / \mathrm{m}$.

\footnotetext{
Corresponding author: rizuan@uthm.edu.my
} 
Current practice to determine fracture energy is through experimental tests such as three-point bending, wedge splitting and disk-shaped compacted tension that require notched specimens. Moreover, due to the advancement in the computational engineering, fracture energy can also be predicted conveniently by using numerical analysis such as finite element method, discrete element method and particle-based method. However, it needs the sophisticated model of constitutive law, representation of softening and crack failure. Therefore, this study aims to investigate the fracture energy of foamed concrete using numerical modelling of the combined finite-discrete element method.

\section{Determination of fracture energy}

Most of experimental investigations of fracture energy follow the recommendation of Hillerborg model [5] by using the three-point bending test. Based on this model, fracture energy can be determined using the following equation:

$$
G_{f}=\frac{U_{0}+m_{g} \Delta_{d}}{B\left(W-a_{0}\right)}
$$

where $U_{0}$ is the area under softening phase of load-displacement profile, $m_{g}$ is the mass of beam, $\Delta_{d}$ is the displacement of fracture (displacement at the ultimate strength), $B$ is specimen width, $W$ is specimen depth and $a_{0}$ is notch depth. However, other models such as introduced by Bazant [6] and Oh et al. [7] can also be adopted to determine fracture energy, where the formula based on the strength and physical properties of concrete.

Numerical modelling is another method to determine fracture energy. This method is very appropriate to predict fracture energy accurately, faster and less tedious. In previous work, Shi and Suzuki [8] conducted numerical modelling of fracture energy using extended fictitious crack model. The model is in two-dimensional based on four-point bending test. Meanwhile, Hanson and Ingraffea [9] also adopted the fictitious model with two-parameter where the non-linear fracture mechanics is taken into account. However, the capability of the numerical modelling is limited to the certain extent of crack opening.

Until recently, numerical modelling of fracture energy of foamed concrete is limited and not well establish. The only available reference is Kozlowski et al. [10] that numerically investigate the fracture energy of foamed concrete using the extended finite element method (XFEM) in Abaqus. In the numerical modelling, the notched beam was simulated under three-point bending test to obtain the fracture processes. It was found that XFEM has successfully modelled the fracture behaviour and provided the decent approximation of load-bearing capacity. This could be a benchmark in the numerical modelling of fracture energy of foamed concrete.

\section{Methodology}

The numerical modelling is based on the notched beam subjected to the three-point bending test. A series of experimental study, as can be seen in Fig. 1, were conducted to provide reliable information, comparison and appraisal for the numerical modelling.

\subsection{Specification of notched beam}

The notched beam was modelled with size of $100 \mathrm{~mm}$ depth (W), $100 \mathrm{~mm}$ width (B) and $500 \mathrm{~mm}$ length (L). The schematic design of notched beam is shown in Fig. 2. The notched beam was produced to fulfill the specific density of $1600 \mathrm{~kg} / \mathrm{m}^{3}$ with targeted compressive strength of $10 \mathrm{MPa}$ to $15 \mathrm{MPa}$. In order to investigate the size effects on fracture energy of 
foamed concrete, the notch depth was increased based on the depth ratio of $\alpha=a_{0} / W$ from 0.15 to 0.75 by an increment of 0.15 . The specification of notch depth can be referred in Table 1.

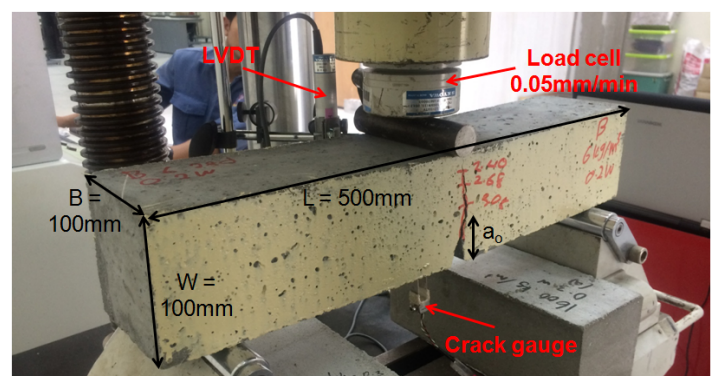

Fig. 1. Experimental study of three-point bending test.

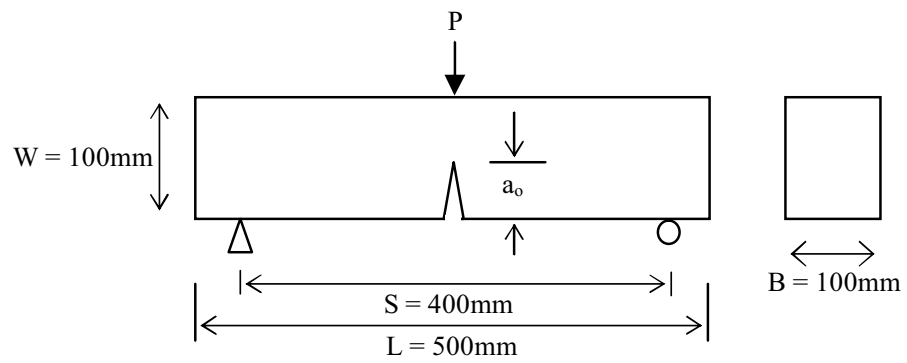

Fig. 2. Dimension of notched beam.

Table 1. Specification of notch depth.

\begin{tabular}{cccc}
\hline No & $\begin{array}{c}\text { Depth Ratio, } \\
\alpha\end{array}$ & $\begin{array}{c}\text { Notch Depth } \\
\mathrm{a}_{0}(\mathrm{~mm})\end{array}$ & Remark \\
\hline 1 & 0.15 & 15 & \\
2 & 0.30 & 30 & Under neutral axis \\
3 & 0.45 & 45 & \\
\hline 4 & 0.60 & 60 & Above neutral axis \\
5 & 0.75 & 75 & \\
\hline
\end{tabular}

\subsection{FDEM modelling}

The combined finite-discrete element method uses a similar algorithm as in the explicit dynamic finite element method with additional parameters for the discrete element insertion [11]. From the basic equation that governs the response of system is given by:

$$
M \ddot{u}\left(t_{n}\right)+C \dot{u}\left(t_{n}\right)+K u\left(t_{n}\right)=f^{e x t}\left(t_{n}\right)
$$

Later, the spatially discretized form of the equilibrium equations at time $t_{n}$ can be rewritten as:

$$
M \ddot{u}\left(t_{n}\right)+C \dot{u}\left(t_{n}\right)=f^{e x t}\left(t_{n}\right)-f^{\mathrm{int}}\left(u\left(t_{n}\right)\right)
$$


where $M$ represents the global mass, $C$ is damping and $K$ is stiffness matrices. The $f^{\text {int }}$ is the vector of the internal resisting forces, and $f^{\text {ext }}$ is the velocity applied forces. The standard notations $\ddot{u}, \dot{u}$ and $u$ signify the acceleration, velocity and displacement vectors in the global domain. The subscript $n$ implies a quantity at time $t_{n}$. In the context of time integration for nonlinear problems, the governing equation generalises the stiffness dependent elastic forces to include both geometric and constitutive nonlinearities to provide internal forces with the structure [12].

Therefore, the internal force vector has to be updated at each time step as well as at each interaction step during the time integration of the equations of motion. Working with system vectors instead of system matrices, which may be added up by the finite element contributions, for the computation of the state variables $u$ and $\dot{u}$, it is possible to increase the number of degrees of freedom and thus large engineering problem can be treated. The diagonal mass matrix, $M$ is defined by:

$$
M=V_{e=1}^{\text {nelem }} A \sum_{i=1}^{\text {nnode }} \int{ }^{e} \rho N_{i}^{T}\left[N_{1}, N_{2}, \ldots, N_{\text {nnode }}\right] d V
$$

and the diagonal damping matrix, $C$ defining the viscous damping term with a constant factor, $\alpha$ as:

$$
C=\alpha M
$$

The damping in Equation (5) will damp out rigid body motion and can thus introduce some undesirable viscous system response.

The common case of a varying time step for an explicit nonlinear dynamic analysis is considered, where the integration time steps length, $\Delta t_{n+l}$ can be identified between the two discrete points in time of $t_{n}$ and $t_{n+1}$. A combination of previous and current mid-point velocities form the second order central difference equation that defines the acceleration state of a known point at a known discrete time $t_{n}$ as:

$$
\ddot{u}\left(t_{n}\right)=\frac{\dot{u}_{n+\frac{1}{2}}-\dot{u}_{n-\frac{1}{2}}}{\Delta t_{n+\frac{1}{2}}}
$$

Through the direct integration of the acceleration term with respect to the time increment measure, the velocity measure associated with a point, at discrete time $t_{n}$ can be approximated as:

$$
\dot{u}\left(t_{n}\right)=\frac{u_{n+\frac{1}{2}}-u_{n-\frac{1}{2}}}{\Delta t_{n+\frac{1}{2}}}=\frac{u_{n+1}-u_{n-1}}{2 \Delta t_{n+\frac{1}{2}}}
$$

The mid-point velocity of the previous and current times can also be further determined as a direction combination of the motion terms at time $t_{n-l}, t_{n}$ and $t_{n+1}$. The mid-point velocity terms are then defined as:

$$
\dot{u}\left(t_{n-\frac{1}{2}}\right)=\frac{u_{n}-u_{n-1}}{\Delta t_{n}} ; \dot{u}\left(t_{n+\frac{1}{2}}\right)=\frac{u_{n+1}-u_{n}}{\Delta t_{n+1}}
$$

Therefore, Equation (7) can be written as follows: 


$$
\dot{u}\left(t_{n}\right)=\frac{\Delta t_{n+1} \dot{u}_{n+\frac{1}{2}}-\Delta t_{n} \dot{u}_{n-\frac{1}{2}}}{2 \Delta t_{n+\frac{1}{2}}}
$$

Upon of substitution of Equation (6) and Equation (9) into Equation (3), the velocity at the current time step is determined in term of the previous time step of velocity, displacement and force. The solution to determine this velocity is given by:

$$
\dot{u}\left(\Delta t_{n+\frac{1}{2}}\right)=\left[2 M+C \Delta t_{n+1}\right]^{-1}[D]
$$

where

$$
[D]=\left(2 M-C \Delta t_{n}\right) \dot{u}_{n-\frac{1}{2}}+2 \Delta t_{n+\frac{1}{2}}\left(f_{n+1}^{\mathrm{int}}-f_{n+1}^{e x t}\right)
$$

or in global velocity at time $t_{n+1}$ by substitute Equation (3) into Equation (9), yields the following expression:

$$
\dot{u}\left(t_{n+1}\right)=\frac{2 M-C \Delta t_{n}}{2 M-C \Delta t_{n+1}} \dot{u}_{n-\frac{1}{2}}+2 \Delta t_{n-\frac{1}{2}} \frac{f_{n}^{e x t}-f_{n}^{\text {int }}}{2 M+C \Delta t_{n+1}}
$$

\subsection{Model of notched beam}

Using the combined finite-discrete element method, the notched beam was modelled as unstructured three-noded element of the surface domains (refer Fig. 3). The advantage of three-noded element is that the crack can be propagated in irregular directions, either through the boundary element (inter-element) or along failure plane (intra-element). The mesh size was initially determined based on the convergence and critical time step. The surrounding area of notch was discretized with size of $3 \mathrm{~mm}$ that has similar size as sand, while the rest area adopting size of $5 \mathrm{~mm}$ to $10 \mathrm{~mm}$.

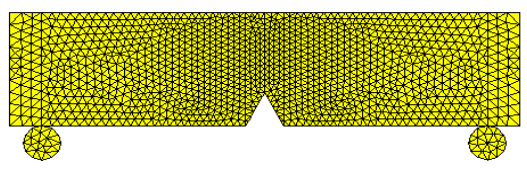

Fig. 3. Unstructured three-noded element of notched beam.

Since the model involves both notched beam and steel support, hence only steel support at left and right sides were constrained. The contact of steel support with notched beam was considered as partially smooth surface. An applied ramp loading was imposed at the midspan of notched beam with speed of $0.5 \mathrm{~mm} / \mathrm{min}$. This speed was maintained until notched beam experiences crack formation that leads to totally collapse. The solution algorithm was based on an explicit central difference solution with the time step of $0.2 \mathrm{msec}$, maximum time step of $1 \mathrm{~s}$ and termination at 200000 steps.

On the other hand, the material properties of foamed concrete and steel support can be referred in Table 2. Foamed concrete was defined as Rotating Crack that only requires elastic properties, tensile strength and strain rate. Meanwhile, the steel support was assigned as fully elastic. Foamed concrete as a quasi-brittle material is represented as continuum from which cracking virtually occurs during the deformation processes. The crack then propagates to all directions when the strength of foamed concrete is degraded. Before 
experiencing any failure, foamed concrete remains in homogeneous elastic state. After the initial yield, the Rotating Crack represents the anisotropic damage evolution by degrading the elastic modulus in the direction of the major principal stress invariant.

Table 2. Material properties of foamed concrete and steel support

\begin{tabular}{cccc}
\hline No. & Properties & Foamed Concrete & Steel Support \\
\hline 1 & Young's modulus, $E(\mathrm{GPa})$ & 12 & 210 \\
2 & Poisson's ratio, $v$ & 0.20 & 0.30 \\
3 & Density, $\rho\left(\mathrm{kg} / \mathrm{m}^{3}\right)$ & 1600 & 7800 \\
4 & Tensile strength, $\sigma_{t}(\mathrm{MPa})$ & 0.56 & - \\
5 & Strain rate & 0.01 & - \\
\hline
\end{tabular}

\section{Results and discussions}

The combined finite-discrete element method is based on continuum and fracture failures. Therefore, the effective stress and crack propagation that occur on the notched beam can be simultaneously observed. Effective stress was observed at the initial time and pre-cracking (refer Fig. 4) to understand the deformation behaviour that happen in the different stages.

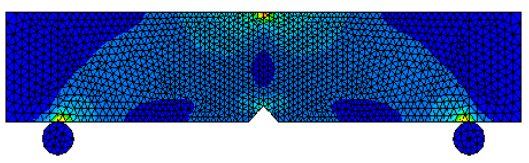

$\mathrm{a}_{0}=15 \mathrm{~mm}$
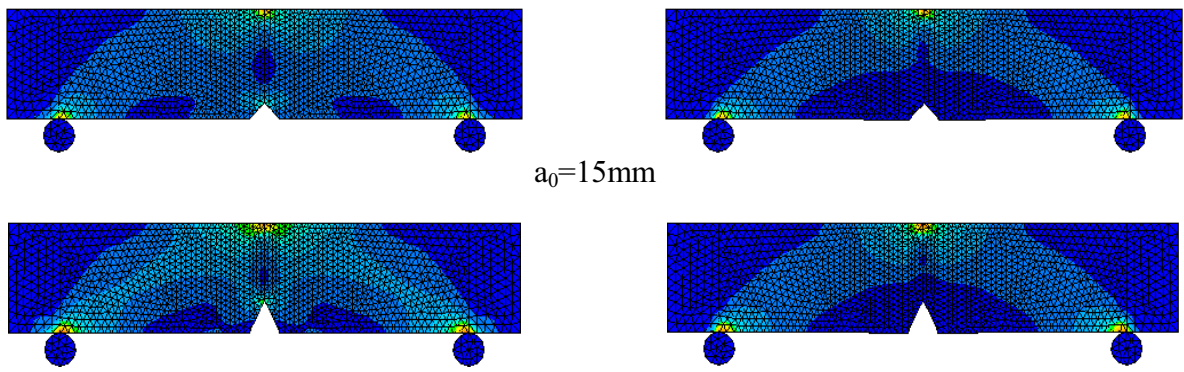

$\mathrm{a}_{0}=30 \mathrm{~mm}$
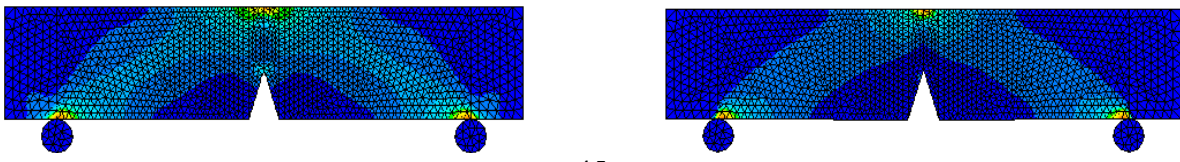

$\mathrm{a}_{0}=45 \mathrm{~mm}$
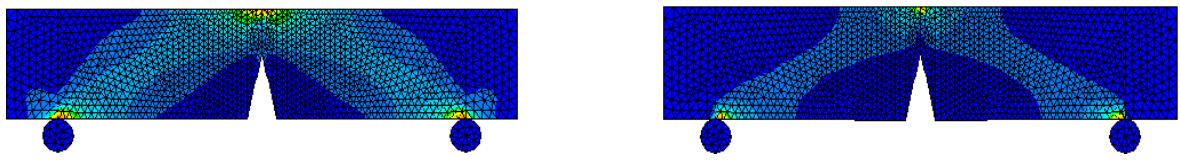

$\mathrm{a}_{0}=60 \mathrm{~mm}$

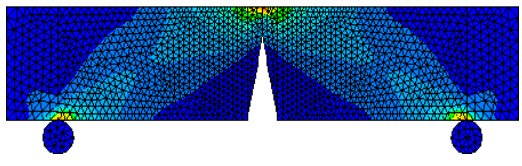

$\mathrm{a}_{0}=75 \mathrm{~mm}$

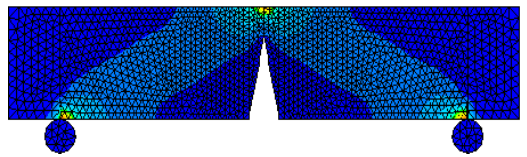

b) pre-cracking

Fig. 4. Stress distribution during loaded stage. 
At the initial time, no cracking was observed and thus notched beam still in the intact condition. Meanwhile, during which the effective stress exceeded the ultimate strength of foamed concrete, cracks start to initiate and propagate from the notch tip. Under the applied loading, the crack was found propagate very slowly.

Since fracture energy is determined using Hillerborg model, the combined finitediscrete element method was setup to give the load-displacement profile as can be seen in Fig. 5. It was observed from the load-displacement profile that the ultimate load decreases when the notch depth becomes deeper. This subsequently affected the area of softening. Any increment on the notch depth corresponds directly on the reduction of the softening area and hence decrease fracture energy. Based on calculation, fracture energy of foamed concrete is $28.30 \mathrm{~N} / \mathrm{m}, 21.28 \mathrm{~N} / \mathrm{m}, 10.45 \mathrm{~N} / \mathrm{m}, 3.59 \mathrm{~N} / \mathrm{m}$ and $1.37 \mathrm{~N} / \mathrm{m}$ for notch depth of $15 \mathrm{~mm}, 30 \mathrm{~mm}, 45 \mathrm{~mm}, 60 \mathrm{~mm}$ and $75 \mathrm{~mm}$ respectively.

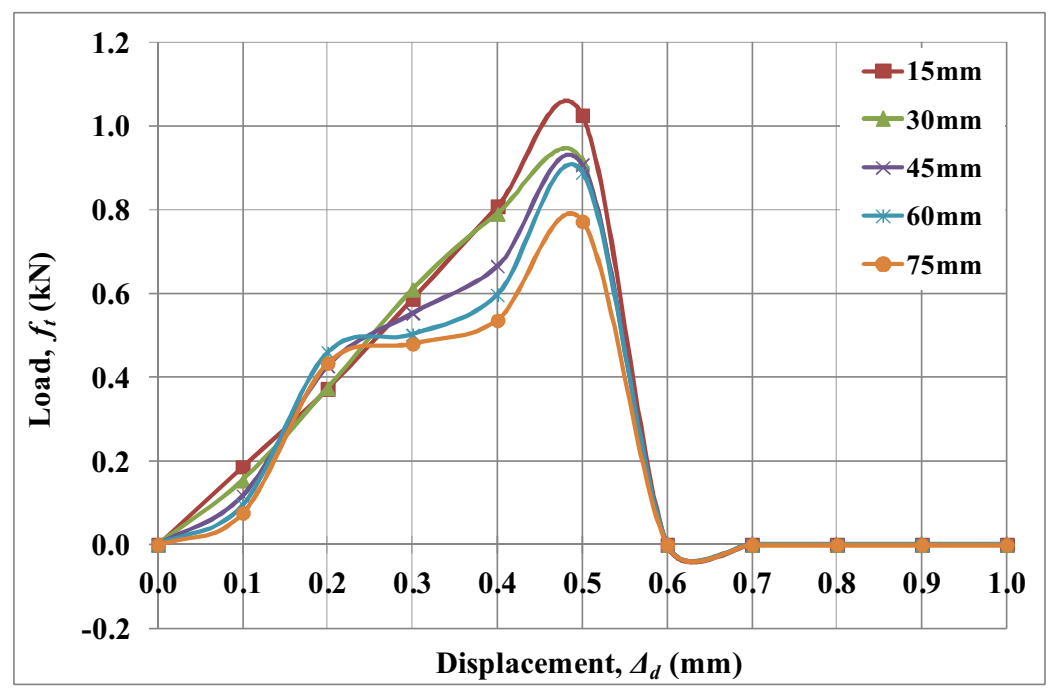

Fig. 5. Load-deflection profile for notched beam subjected three-point bending.

According to Abd Rahman et al. [2], the fracture energy of foamed concrete is about $18 \mathrm{~N} / \mathrm{m}$ to $25 \mathrm{~N} / \mathrm{m}$ for $\mathrm{V}$-notch with the depth of $30 \mathrm{~mm}$. It should be noted here that this fracture energy is for notched beam with size $150 \mathrm{~mm}$ depth (W), $150 \mathrm{~mm}$ width (B) and $700 \mathrm{~mm}$ length $(\mathrm{L})$. In the numerical modelling, fracture energy for the similar notch is $21.28 \mathrm{~N} / \mathrm{m}$. Therefore, the fracture energy that obtained from numerical modelling using similar notch is convincing and favourable. Meanwhile, a comparison of fracture energy from experimental study and numerical modelling is depicted in Fig. 6. Both results were also fitted to produce simple equations based on the notch depth.

Based on the comparison, the fracture energy from numerical modelling is significantly different with experimental study. For notch depth below than $22 \mathrm{~mm}$, numerical modelling produces upper bound results. However, numerical modelling underestimates the fracture energy when notch depth increased. The error, although still acceptable, might be caused by the boundary condition between notched beam and steel support which relatively softer than actual. The material properties used in this numerical model are not based on real tests but rather derived from reasonable assumptions. Other than that, it was found that instability of elements occurs during the energy dissipation that disturbs the crack 
propagation. Table 3 shows the errors of numerical modelling, where notch depth located below than neutral axis has favourable agreement.

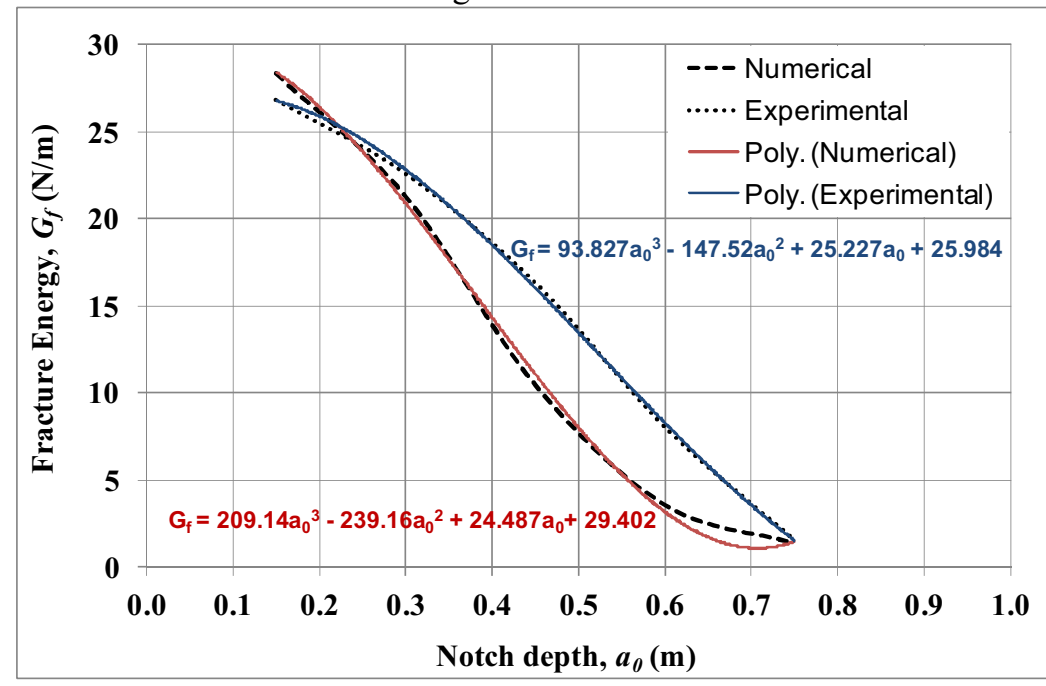

Fig. 6. Comparison of fracture energy between experimental and numerical study.

Table 3. Error in fracture energy of foamed concrete

\begin{tabular}{ccccc}
\hline No. & $\begin{array}{c}\text { Notch Depth } \\
\mathrm{a}_{\mathrm{o}}(\mathrm{mm})\end{array}$ & $\begin{array}{c}\text { Fracture Energy Experimental } \\
\mathrm{G}_{\mathrm{f}, \mathrm{exp}}(\mathrm{N} / \mathrm{m})\end{array}$ & $\begin{array}{c}\text { Fracture Energy Numerical } \\
\mathrm{G}_{\mathrm{f}, \text { num }}(\mathrm{N} / \mathrm{m})\end{array}$ & $\begin{array}{c}\text { Error } \\
(\%)\end{array}$ \\
\hline 1 & 15 & 26.82 & 28.30 & 5.51 \\
2 & 30 & 22.59 & 21.28 & 5.80 \\
3 & 45 & 16.34 & 10.45 & 36.05 \\
4 & 60 & 8.06 & 3.59 & 55.46 \\
5 & 75 & 1.56 & 1.37 & 12.18 \\
\hline
\end{tabular}

\section{Conclusions}

Numerical modelling of fracture energy of foamed concrete was performed using the combined finite-discrete element method. The fracture energy was successfully achieved by employing designated material criteria of Rotating-Crack for foamed concrete and elastic model for steel support. The notched beam was modelled using unstructured three-noded mesh element and imposed by loading as similar as three-point bending test. The numerical modelling measures the fracture energy based on Hillerborg model, where the area of loaddisplacement profile, maximum deflection, mass and dimension of notched beam become dominant parameters.

It was found that the fracture energy of foamed concrete significantly decreased by the notch depth. Although the numerical modelling produces a reliable prediction of fracture energy, the results considerably lower than experimental study. This happen due to identified factors such as the contact interaction between foamed concrete and steel support, material properties and instability on the energy dissipation. However, this approach on numerical modelling of fracture energy of foamed concrete is extremely valuable and the accuracy of results can be further enhanced. 
Authors would like to thanks Ministry Education of Malaysia and Universiti Tun Hussein Onn Malaysia for the financial and facilities supports. This study was conducted under Fundamental Research Grant Scheme, FRGS Code 1219.

\section{References}

[1] N. Abd Rahman, Z.M. Jaini, N.A. Abd Rahim and S.A. Abd Razak, An experimental study on the fracture energy of foamed concrete using v-notched beams, Proc. of the Int. Civil and Infrastructure Engineering Conference, Springer, Singapore, 2015, 97 108

[2] N. Abd Rahman, Z.M. Jaini and N.N.M. Zahir, Fracture energy of foamed concrete by means of the three-point bending test on notched beam specimens, ARPN Journal of Engineering and Applied Sciences,10(15), 6562-6570 (2015)

[3] M. Kozlowski, M. Kadela and A. Kukielka, Fracture energy of foamed concrete based on three-point bending test on notched beams, Procedia Engineering, 108, 349-354 (2015)

[4] Z.M. Jaini, S.N. Mokhatar, A.S.M. Yusof, S. Zulkiply and M.H. Abd Rahman, Effect of pelletized coconut fibre on the compressive strength of foamed concrete, MATEC Web of Conference, 47, 01013 (2016)

[5] A. Hillerborg, The theoretical basis of a method to determine the fracture energy of concrete, Materials and Structure, 18(4), 291-296 (1985)

[6] Z.P. Bazant, Concrete fracture models testing and practice, Engineering Fracture Mechanics, 69, 165-205 (2002)

[7] B.H. Oh, S.Y. Jang and H.K. Byun, Prediction of fracture energy of concrete, KCI Concrete Journal, 11(3), 211-221 (1999)

[8] Z. Shi and M. Suzuki, Numerical studies on load-carrying capacities of notched concrete beams subjected to various concentrated loads, Construction and Building Materials, 18(3), 173-180 (2004)

[9] J.H. Hanson and A.R. Ingraffea, Using numerical simulations to compare the fracture toughness values for concrete from the size-effect, two-parameter and fictitious crack model, Engineering Fracture Mechanics, 70, 1015-1027 (2003)

[10] M. Kozlowski, M. Kadela and M. Gwozdz-Lason, Numerical fracture analysis of foamed concrete beam using XFEM method, Applied Mechanics and Materials, 837, 183-185 (2016)

[11]Z.M. Jaini, Y.T. Feng, D.R.J. Owen and S.N. Mokhatar, Fracture failure of reinforced concrete slabs subjected to blast loading using the combined finite-discrete element method, Latin American Journal of Solids and Structures, 13(6), 1086-1106 (2016)

[12]M.G. Cottrell, The Development of Rational Computational Strategies for the Numerical Modelling of High Velocity Impact, PhD Thesis, Swansea University, United Kingdom, (2002) 